\title{
THE MEDITERRANEAN ACTION PLAN
}

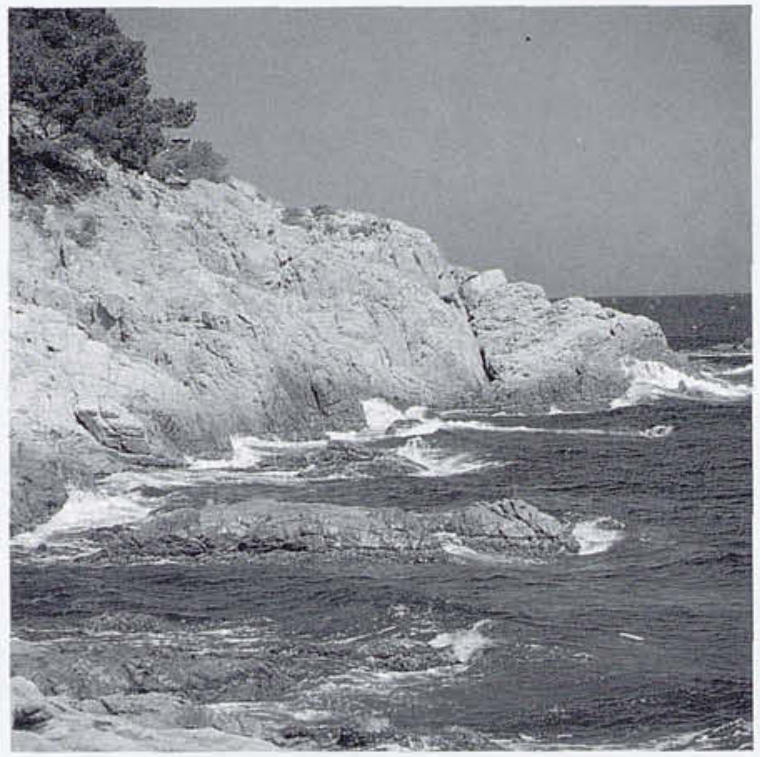

\author{
THE MEDITERRANEAN, CRADLE OF WESTERN CIVILIZATION AND \\ A CROSSROADS FOR EUROPEAN, ASIAN AND AFRICAN CULTURES, \\ IS TODAY A MICROCOSM WHICH IS UNDERGOING A PROCESS \\ OF RAPID TRANSFORMATION AND DEVELOPMENT, SPEEDED UP \\ BY THE ACTIVITY OF THE MORE THAN 100 MILLION PEOPLE WHO \\ LIVE ALONG ITS SHORES AND WHO COULD REACH THE FIGURE \\ OF 200 MILLION BY THE YEAR 2000.
}

JOAN ALBAIGES DIRECTOR OF THE BARCELONA CENTRE D.INVESTIGACIÓ I DESENVOLUPAMENT

$\mathbf{T}$ he Mediterranean, cradle of western civilization and a crossroads for European, African and Asian cultures, is today a microcosm which is undergoing a process of rapid transformation and development, speeded up by the activity of the more than 100 million people who live along its shores and who could reach the figure of 200 million by the year 2000 . The threat this poses for the ecological balance of the region is obvious. The Mediterranean is virtually a lake, whose waters are renewed every 80 or 100 years, at the same time as they are subjected to a permanent process of concentration due to the negative balance between evaporation and rainfall, compensated by the entry of water from the Atlantic.

At the end of the sixties and the beginning of the seventies, when people began to be aware of environmental problems thanks to the Stockholm United Nations Conference on the Human Environment (1972), the Mediterranean became the focal point of public attention. Alarming signs of degradation were detected and very soon there was talk of the death of the Mediterranean. It was obvious, as J. Rostand said, that the sea could not be both dumping-ground and larder for mankind and that something had to be done.

Wishing to apply the ideas of the Stockholm conference, the region's governments asked the United Nations Environment Programme (UNEP) for help in developing a plan to stop the degradation of the Mediterranean and, espe- 


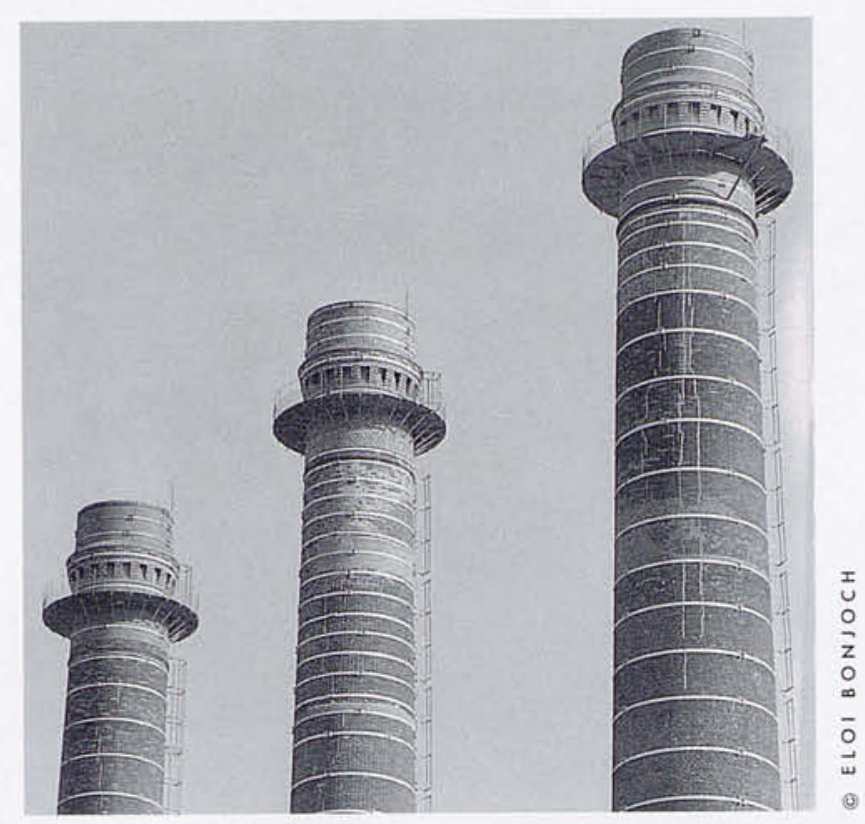

cially, the coastal zone. Representatives of the different states met in Barcelona in 1975 to decide on an Action Plan. The Plan requested: 1) that the states involved sign a series of legally binding agreements, 2) the creation of a network to control and investigate contamination and 3) the preparation of a socio-economic programme to balance the principal developmental aims and the conservational needs of the environment.

One year later, in 1976, fifteen governments of the Mediterranean countries and the European Economic Community signed a Protocol in Barcelona for the protection of the sea against contamination, known as the Barcelona Convention. Ten years later, seventeen countries, that is, all except Albania, had ratified it. The Convention committed the participating states to take measures to prevent, reduce and combat the contamination of the marine environment, adjusting their respective legislations to its spirit and aims. The convention also passed two resolutions, one on leaks from boats and planes and the other on cooperation in cases of emergency. A third resolution, considered the most important but also the most difficult to put into practice, came into force in 1983: the Protocol regarding dumping from the continent, that is to say, urban, agricultural and industrial, as well as atmospheric waste.

The second objective, the creation of a network of contamination control, re- quired the participation of scientists from all the region. In the first phase, a pilot plan (MED POL) was established in which scientists from 83 laboratories in 16 countries built up a bank of information on Mediterranean contamination and identified its chief causes. This phase was undertaken between 1976 and 1980 and needed an extensive programme of laboratory work, staff training and convalidation of methods of analysis.

On the basis of the information gathered, a second phase was started in 1981 (MED POL II), which will last until 1990, to continue the control of pollutants, their occurrence and effects, in given areas. Up to the present moment, seven countries, including Spain, have been carrying it out, covering the whole of the Mediterranean coast, and with an important part being played by the research centres of Catalonia (Centre d'Estudis Avançats de Blanes, Centre d'Investigació i Desenvolupament, etc.).

At the same time, an investigation programme is being started to study the complex processes of pollutant transformation and transportation and, especially, to discover the system's regenerational capacity, with a view to laying down the necessary scientific bases for the elaboration and application of the resolutions, rules and criteria regarding environmental quality, which will have to be adopted.

Finally, the Blue Plan, started in 1979 as the main socio-economic factor in the
Action Plan, attempts to help the region's governments to reach decisions that take into account the conservation of the environment within established targets of cultural and economic development. Over the last few years, the Blue Plan has allowed an examination of the present trends in development in the region and several reports have been published on fresh water supplies, industrial growth, energy, population growth, town-planning, rural development, etc., that will form the basis, at the end of 1987, of several models or scenes of evolution in the region according to the different development policies adopted. Thanks to all these studies and instruments, today we can be sure that the Mediterranean sea is not dead, not by a long way, though it is in danger.

The response of the Mediterranean countries to the Barcelona Convention has served as a model for similar initiatives in other parts of the world, which now make up the UNEP Regional Seas Programme in which 130 countries take part, and to show the world that the UN system can supply practical solutions to multinational problems. At a moment when we are having difficulties in reaching international agreement on peace and the progress of peoples, this is an example to follow. Let it not be the case that, as has been said, "The ocean promises to be the ultimate challenge to nations to co-exist on a watery planet whirling through space". 